\title{
Pertumbuhan Bibit Tanaman Kelor (Moringa oleifera Lam.) Asal Biji pada Berbagai Fase Pindah Tanam Semai
}

\section{Growth of Drum Stick (Moringa oleifera Lam.) SeedlingDerivated fromSeed at Different Phases of Transplanting}

\author{
Samsul Hilal*1), I Gusti Made Arya Parwata ${ }^{2)}$, Bambang Budi Santoso*2) \\ ${ }^{1)}$ Program Studi Agroekoteknologi Fakultas Pertanian UNRAM \\ ${ }^{2)}$ Kelompok Peneliti Bidang Ilmu Pertanian Lahan Kering, Fakultas Pertanian UNRAM \\ *Correspondence author: Samsul.hila164@yahoo.com dan bbsjatropha1963@gmail.com
}

Manuscript received: 09-04-2018. Accepted: 02-06-2018

\begin{abstract}
ABSTRAK
Penelitian ini bertujuan untuk mengetahui pertumbuhan bibit kelor asal biji dari berbagai fase pindah tanam semai, yang telah dilakukan pada April-Juli 2017 di Kelurahan Dasan Agung, Kecamatan Selaparang, Kota Mataram, Nusa Tenggara Barat. Percobaan menggunakan Rancangan Acak Lengkap satu faktor yaitu: tanam langsung, pindah tanam saat fase pancing, pindah tanam saat fase jarum, pindah tanam saat fase kuncup, dan pindah tanam saat fase mekar daun sempurna. Hasil penelitian menunjukkan bahwa saat pindah tanam semai berpengaruh tidak nyata terhadap pertumbuhan bibit tanaman kelor, namun dari sudut pandang agronomis, saat pindah tanam fase pancing dan fase jarum merupakan fase yang lebih baik dibandingkan ketiga fase lainnya.
\end{abstract}

Kata kunci: tanam langsung, fase semai, pembibitan, perbanyakan.

\begin{abstract}
This research was aimed to find out the growth of seedling drum stick (Moringa oleifera Lam.) originated from seed at different phases of transplanting. Has been done on April-Juli 2017 at Dasanagung, Mataram, West Nusa Tenggara. This study used a complete randomized design (CRD) of one factor, namely: direct seed planting, fishing phase, needle phase, bud phase, and the first leaf phase blooms perfect. The results of this study showed that phase of transplanting has no significant effect on growth of seedling moringa plant. Both of fhising phase and needle phase are better of five transplanting's phase.
\end{abstract}

Key words: direct planting, seedling phase, nursery, propagation. 


\section{PENDAHULUAN}

Kelor dikenal di seluruh dunia sebagai tanaman bergizi dan ditetapkan sebagai salah satu pangan alternatif untuk mengatasi masalah gizi (Broin, 2010). Selain sebagai sumber gizi, tanaman kelor dapat digunakan untuk memperbaiki lingkungan, terutama untuk memperbaiki kualitas air, karena bijinya dapat berperan sebagai koagulan alami (Tiea et al. (2015). Sedangkan Santoso dan Parwata (2017), menyatakan bahwa, tanaman kelor menjadi pilihan yang layak untuk dikembangkan sebagai sumber pangan sehat dan juga sumber energi.

Sehubungan dengan banyaknya manfaat dari tanaman kelor, maka pengembangan tanaman ini sangat perlu dilakukan. Untuk mendapatkan hasil tanaman kelor yang berkualitas, penyediaan bibit berkualitas sangat diperlukan. Teknik pembibitan untuk menghasilkan bibit berkualitas merupakan hal penting bagi pengembangan tanaman tahunan seperti kelor. Pembibitan diartikan sebagai usaha mempersiapkan bahan tanaman berupa bibit yaitu tanaman muda melalui penanaman biji (generatif) maupun bagian vegetatif tanaman (Santoso et al., 2017).

Pembibitan tanaman secara generatif dapat dilakukan secara langsung dan tidak langsung. Kedua teknik pembibitan tersebut memiliki kekurangan dan kelebihan masingmasing, namun untuk mendapatkan bibit berkualitas, pemilihan salah satu dari dua teknik pembibitan tersebut sangat tergantung pada viabilitas benih yang digunakan. Bilamana benih memiliki viabilitas yang baik, maka pembibitan langsung di lapangan dapat dipilih, namun bilamana viabilitasbenih rendah, maka pembibitan tidak langsung dipilih sebagai usaha mempersiapkan bibit tanaman yang bermutu (Santoso dan Purwoko, 2008). Lebih lanjut dikatakan Santoso dan Parwata (2017) bahwa variabilitas dalam hal daya kecambah dan kecepatan berkecambah biji kelor dikarenakan adanya perbedaan tingkat kematangan biji-biji yang jumlahnya cukup banyak pada buah, maka pemilihan teknik pembibitan sangat diperlukan. Hal ini sangat menentukan kualitas dan keragaman bibit (Sadjad, 1989).

Penanaman secara langsung, umumnya dilakukan pada benih tanaman yang memiliki ukuran sedang hingga besar dan jumlah persediaan benihnya banyak, kepastian daya kecambahnya tinggi, dan biasanya merumitkan dalam perawatannya pada saat persemaian. Sementara itu, pembibitan secara tidak langsung lebih mudah dalam perawatan karena hanya dilakukan pada bak media kecambah saja sehingga lebih mudah dalam perawatannya sebelum pindah tanam ke polibag pembibitan.

Pemeliharaan awal dimasa pembibitan dapat dilakukan dengan intensif dalam skala kecil dibandingkan dengan penanaman secara langsung dan ukuran biji yang tidak seragam dapat menyebabkan pertumbuhan bibit tidak serentak bahkan tidak tumbuh. Oleh karena itu hendaknya tanaman dengan asal bahan tanam biji, disemaikan terlebih dahulu sebelum ditanam dilahan. Pada tanaman jarak pagar, Santoso dan Purwoko (2008), melaporkan bahwa fase perkecambahan atau semai saat penyapihan berpengaruh nyata terhadap panjang akar tunjang, panjang akar lateral, dan berat kering akar. Sedangkan Hartmann et al.(1997) dan Acquaah (2002) menyatakan bahwa penentuan umur semai yang tepat untuk pindah tanam sangat diperlukan agar tidak terlambat atau terlalu awal, karena umur pindah tanam semai menentukan pertumbuhan bibit baik kualitas maupun kuantitas. Artikel ini memaparkan hasil 
penelitian pengaruh saat fase pertumbuhan semai pindah tanam ke polibag pembibitan terhadap pertumbuhan bibit tanaman kelor.

\section{BAHAN DAN METODE}

Tempat penelitian dan bahan tanam

Percobaan ini dilaksanakan mulai pada April-Juli 2017, di lahan pembibitan di Kelurahan Dasan Agung, Kecamatan Selaparang, Kota Mataram, Provinsi Nusa Tenggara Barat, pada ketinggian $16 \mathrm{~m}$ dpl.

Bahan tanam yang digunakan berupa biji yang diperoleh dari tanaman kelor yang tumbuh dipekarangan rumah penduduk di Desa Panggung, Kabupaten Lombok Utara. Tanaman telah berumur \pm 15 tahun, dan tampak tumbuh subur. Biji-biji dikumpulkan dari buah yang telah kering dan biji yang diambil adalah biji-biji yang berada di bagian tengah buah setelah dibagi 3 bagian.Biji-biji terkumpul kemudian dikeringanginkan selama 2 hari, kemudian disimpan dalam kantong plastik (PP) transparan pada ruangan berfasilitas Air Conditioner.

\section{Rancangan Percobaan}

Percobaan menggunakan Rancangan Acak Lengkap (RAL), dengan lima perlakuan, yaitu berupa fase perkembangan semai: a) biji langsung tanam, b) saat semai fase pancing, c) saat semai fase jarum, d) saat semai fase kuncup, dan e) saat semai fase daun pertama mekar sempurna. Setiap perlakuan diulang $5 \mathrm{kali}$ dan setiap ulangan memiliki5 unit seri percobaan sehingga keseluruhan terdapat 125 unit percobaan.

\section{Pelaksanaan Percobaan}

Persiapan Benih. Biji yang dipilih sebagai calon benih adalah biji yang sehat penampilan biji tidak keriput, cacat atau rusak dan berwarna coklat. Sebelum ditanam, benih direndam terlebih dahulu selama satu malam.

Persiapan Media Semai dan Tanam. Mediapersemaian yang digunakan dalam percobaan ini adalah media tanam campuran pasir, tanah dan sekam segar dengan perbandingan 2:2:1 (v:v).

Sedangkan untuk media pembibitan, digunakan campuran media pupuk kandang sapi, sekam padi dan tanah dengan perbandingan 1:1:1 (v:v), kemudian media dicampur hingga merata dan dimasukkan ke dalam polibag berukuran $20 \mathrm{~cm}$ x $26 \mathrm{~cm}$. Tanah yang digunakan yaitu berasal dari tanah sawah sedalam 20-25 cm (tanah tipe Regosol merah kuning).

Persemaian dan Penanaman. Persemaian dilakukan dengan membenamkan biji kelor sedalam $2 \mathrm{~cm}$ ke dalam media dalam bak kecambah dan setiap bak kecambah diisi dengan 50 biji.

Perlakuan biji tanam langsung, dilakukan dengan dibenamkan biji ke media dalam polibag pada kedalaman $2 \mathrm{~cm}$. Tiap polibag ditanami masing-masing 2 biji.Penjarangan dilakukan ketika biji kelor sudah tumbuh dengan cara memilih salah satu bibit yang paling baik pertumbuhannya. Semai yang sudah tumbuh dipindah tanam ke polibag sesuai perlakuan. Pindah tanam dilakukan dengan mencabut semai secara hati-hati dari media persemaian dengan bantuan bilah bambu agar akar bibit tidak rusak, satu polibag ditanami satu semai kelor. 
Pemeliharaan Persemaian dan Bibit. Pemeliharaan yang dilakukan satu kali dalam sehari setiap sore hari. Penyulaman dilakukan paling lambat 7 hari setelah tanam. Penyulaman terhadap semaian yang dipindah tanam dilakukan bilamana dalam 7 hari setelah pintah tanam semai tampak mati. Penyiangan dilakukan dengan cara mencabut gulma yang tumbuh di dalam media pembibitan. Pemupukan dilakukan pada saat bibit umur 14 hari setelah pindah tanam menggunakan pupuk Phonska 15-15-15 dengan dosis 5 gram setiap polibag dengan cara membuat larikan dengan jarak kurang lebih 2,5 cm dari pangkal bibit. Adapun hama seperti bekicot dan belalang dikendalikan menggunakan tangan, sedangkan untuk penyakit dikendalikan dengan cara disemprot menggunakan insektisida Urakron dengan konsentrasi aplikasi $2 \mathrm{ml} . \mathrm{L}^{-1}$.

\section{Variabel Pengamatan dan Analisis Data}

Jumlah daun, dengan menghitung jumlah daun yang sudah mekar sempurna. Tinggi tanaman, diukur menggunakan penggaris dari pangkal batang sampai ujung tertinggi. Diameter batang, diukur dengan menggunakan jangka sorong pada pangkal dan bagian atas batang. Panjang akar primer diukur dari pangkal akar hingga ujung akar dengan menggunakan penggaris.Jumlah akar lateral, dihitung adalah akar yang tumbuh dari akar primer. Panjang akar lateral, yang diukuradalah akar yang tumbuh dari akar primer menggunakan penggaris. Bobot berangkasan bibit diukur/ditimbang dengan memisahkan bagian tajuk dan akar bibit, yaitu terhadap bobot segar maupun bobot kering. Untuk mendapatkan bobot berangkasan kering, tajuk dan akar bibit dioven hingga beratnya konstan. Selanjutnya rasio tajuk-akar dihitung dengan membandingkan bobot berangkasan kering tajuk dan akar bibit.

Analisis data menggunakan Anova 5\% dan diuji lanjut apabila ada pengaruh dari perlakuan dengan uji BNJ (Beda Nyata Jujur) pada taraf $5 \%$.

\section{HASIL DAN PEMBAHASAN}

Secara umum, hasil penelitian menunjukkan bahwa saat pindah tanam (penyapihan) semai berpengaruh tidak nyata terhadap pertumbuhan bibit kelor. Pengaruh nyata tampak pada variabel tinggi bibit saat berumur 14 hspt (hari setelah pindah tanam), diameter batang saat berumur $28 \mathrm{hspt}$, bobot kering akar umur $30 \mathrm{hspt}$, rasio tajuk-akar saat berumur $30 \mathrm{hspt}$, dan 60 hspt.

Tabel 1. Jumlah daun bibit kelor pada berbagai fase pindah tanam semai

\begin{tabular}{lcccccc}
\hline \multirow{2}{*}{ Perlakuan } & \multicolumn{6}{c}{ Jumlah daun bibit (helai) saat umur } \\
\cline { 2 - 7 } & $14 \mathrm{hspt}$ & $28 \mathrm{hspt}$ & $42 \mathrm{hspt}$ & $56 \mathrm{hspt}$ & $70 \mathrm{hspt}$ & $84 \mathrm{hspt}$ \\
\hline Biji langsung tanam & 6.32 & 10.20 & 13.25 & 10.35 & 10.93 & 10.80 \\
Semai fase pancing & 6.80 & 10.76 & 13.40 & 11.45 & 12.73 & 10.80 \\
Semai fase jarum & 6.72 & 11.12 & 13.60 & 11.90 & 12.53 & 11.13 \\
Semai Fase kuncup & 6.40 & 10.36 & 13.20 & 12.69 & 11.40 & 9.46 \\
Semai Fase daun pertama & 6.48 & 9.84 & 12.75 & 12.69 & 12.66 & 11.53 \\
mekar sempurna & & & & & & - \\
\hline \multicolumn{1}{c}{ BNJ 5\% } & - & - & - & - & & - \\
\hline
\end{tabular}

Pada Tabel 1 tampak bahwa saat pindah tanam semai berpengaruh tidak nyata terhadap jumlah daun bibit kelor selama 3 bulan periode pembibitan. Pada Tabel 2 tampak 
bahwa bibit yang dipindah pada fase daun pertama mekar sempurna memiliki hasil paling tinggi $(21.22 \mathrm{~cm})$ dan berbeda nyata dengan semua fase pindah tanam lainnya. Pada pengamatan selanjutnya, tinggi bibit tidak dipengaruhi oleh fase pindah tanam semai.

Tabel 2. Tinggi bibit tanaman kelor pada berbagai fase pindah tanam semai

\begin{tabular}{lcccccc}
\hline \multirow{2}{*}{ Perlakuan } & \multicolumn{7}{c}{ Tinggi bibit (cm) saat umur } \\
\cline { 2 - 7 } & $14 \mathrm{hspt}$ & $28 \mathrm{hspt}$ & $42 \mathrm{hspt}$ & $54 \mathrm{hspt}$ & $70 \mathrm{hspt}$ & $84 \mathrm{hspt}$ \\
\hline Biji langsung tanam & $19,96 \mathrm{~b}$ & 32,70 & 53,95 & 66,65 & 90,32 & 100,28 \\
Semai fase pancing & $19,98 \mathrm{~b}$ & 31,30 & 53,10 & 65,97 & 86,70 & 93,47 \\
Semai fase jarum & $19,07 \mathrm{~b}$ & 30,18 & 50,74 & 65,96 & 85,42 & 92,88 \\
Semai fase kuncup & $19,92 \mathrm{~b}$ & 31,90 & 51,37 & 63,68 & 89,59 & 100,53 \\
Semai fase daun pertama & $21,22 \mathrm{a}$ & 31,87 & 48,18 & 60,28 & 77,58 & 83,27 \\
mekar sempurna & & & & & & - \\
\hline \multicolumn{1}{c}{ BNJ 5\% } & 1,19 & - & - & - & - & - \\
\hline
\end{tabular}

Keterangan: Angka-angka diikuti notasi yang sama pada kolom umur tanam yang sama tidak bebeda nyata berdasarkan uji BNJ pada taraf 0,05

Tabel 3. Diameter batang bibit tanaman kelor pada berbagai fase pindah tanam semai

\begin{tabular}{lcccccc}
\hline \multirow{2}{*}{\multicolumn{1}{c}{ Perlakuan }} & \multicolumn{6}{c}{ Diameter batang bibit (cm) saat umur } \\
\cline { 2 - 7 } & $14 \mathrm{hspt}$ & $28 \mathrm{hspt}$ & $42 \mathrm{hspt}$ & $56 \mathrm{hspt}$ & $70 \mathrm{hspt}$ & $84 \mathrm{hspt}$ \\
\hline Biji langsung tanam & 0.20 & $0.27 \mathrm{ab}$ & 0.42 & 0.49 & 0.57 & 0.63 \\
Semai fase pancing & 0.20 & $0.29 \mathrm{a}$ & 0.41 & 0.48 & 0.55 & 0.60 \\
Semai fase jarum & 0.21 & $0.27 \mathrm{ab}$ & 0.42 & 0.47 & 0.54 & 0.58 \\
Semai fase kuncup & 0.21 & $0.27 \mathrm{ab}$ & 0.40 & 0.46 & 0.56 & 0.61 \\
Semai fase daun pertama & 0.18 & $0.24 \mathrm{~b}$ & 0.37 & 0.43 & 0.47 & 0.54 \\
mekar sempurna & & & & & & - \\
\hline \multicolumn{1}{c}{ BNJ 5\% } & - & 0.04 & - & - & - \\
\hline
\end{tabular}

Keterangan: Angka-angka diikuti notasi yang sama pada kolom umur tanam yang sama berbeda nyata tidak berdasarkan uji BNJ pada taraf 0,05

Pada Tabel 3 tampak bahwa pada umur 28 hspt, bibit yang dipindah pada fase pancing memiliki diameter batang paling besar yaitu $0.29 \mathrm{~cm}$ dan berbeda tidak nyata dengan bibit yang dipindah pada fase jarum, fase kuncup, dan biji langsung tanam. Diameter batang bibit pada pengamatan sebelum dan sesudah umur $28 \mathrm{hspt}$ berbeda tidak nyata di antara sama perlakuan.

Tabel 4. Berat berangkasan akar bibit tanaman kelordari berbagai fase pindah tanam semai

\begin{tabular}{lcccccc}
\hline \multirow{2}{*}{\multicolumn{1}{c}{ Perlakuan }} & \multicolumn{3}{c}{ Bobot segar akar (g) saat umur } & \multicolumn{3}{c}{ Bobot kering akar (g) saat umur } \\
\cline { 2 - 7 } & $30 \mathrm{hspt}$ & $60 \mathrm{hspt}$ & $90 \mathrm{hspt}$ & $30 \mathrm{hspt}$ & $60 \mathrm{hspt}$ & $90 \mathrm{hspt}$ \\
\hline Biji langsung tanam & 5.18 & 17.68 & 49.80 & $0.64 \mathrm{a}$ & 1.73 & 6.45 \\
Semai fase pancing & 4.96 & 20.60 & 44.19 & $0.46 \mathrm{ab}$ & 2.50 & 6.29 \\
Semai fase jarum & 3.99 & 22.12 & 37.72 & $0.42 \mathrm{ab}$ & 2.53 & 5.09 \\
Semai fase kuncup & 4.39 & 15.56 & 38.38 & $0.44 \mathrm{ab}$ & 1.92 & 5.25 \\
Semai fase daun pertama & 2.96 & 10.31 & 25.70 & $0.20 \mathrm{~b}$ & 1.62 & 3.22 \\
mekar sempurna & & & & & & - \\
\hline \multicolumn{1}{c}{ BNJ 5\% } & - & - & - & 0,34 & - \\
\hline
\end{tabular}

Keterangan: Angka-angka diikuti notasi yang sama pada kolom umur tanam yang sama tidak bebeda nyata berdasarkan uji BNJ pada taraf 0,05 
Pada Tabel 4 tampak bahwa selama periode percobaan, pindah tanam semai berpengaruh tidak nyata terhadap berat berangkasan segar akar. Sedangkan pada pengamatan berat berangkasan kering akar, saat pindah tanam semai berpengaruh nyata hanya pada bibit umur $30 \mathrm{hspt}$, biji langsung tanam memiliki nilai rata-rata tertinggi $(0.64 \mathrm{~g})$ dan tidak berpengaruhnyata dengan semai fase pancing, semai fase jarum, dan semai fase. Pada pengamatan selanjutnya bobot kering akar tidak dipengaruhi oleh pindah tanam semai.

Tabel 5. Bobot berangkasan tajuk bibit tanaman kelor $(\mathrm{g})$ dari berbagai fase pindah tanam semai

\begin{tabular}{|c|c|c|c|c|c|c|}
\hline \multirow[t]{2}{*}{ Perlakuan } & \multicolumn{3}{|c|}{ Bobot segar tajuk (g) saat umur } & \multicolumn{2}{|c|}{ Bobot kering tajuk (g) } & saat umur \\
\hline & $30 \mathrm{hspt}$ & $60 \mathrm{hspt}$ & $90 \mathrm{hspt}$ & $30 \mathrm{hspt}$ & $60 \mathrm{hspt}$ & $90 \mathrm{hspt}$ \\
\hline Biji langsung tanam & 5.52 & 30.28 & 52.24 & 0.53 & 3.98 & 7.67 \\
\hline Semai fase pancing & 6.39 & 22.81 & 35.44 & 0.58 & 3.30 & 5.11 \\
\hline Semai fase jarum & 4.80 & 27.84 & 50.09 & 0.47 & 3.79 & 7.19 \\
\hline Semai fase kuncup & 5.87 & 17.51 & 34.75 & 0.53 & 2.46 & 5.28 \\
\hline $\begin{array}{l}\text { Semai fase daun pertama } \\
\text { mekar sempurna }\end{array}$ & 4.81 & 19.88 & 25.68 & 0.59 & 3.36 & 4.18 \\
\hline BNJ 5\% & - & - & - & - & - & - \\
\hline
\end{tabular}

Pada Tabel 5 tampak bahwa pindah tanam semai berpengaruh tidak nyata terhadap bobot segar tajuk bibit kelor selama tiga bulan periode percobaan. Begitu juga pada bobot kering tajuk, saat pindah tanam semai berpengaruh tidak nyata terhadap bobot kering tajuk selama tiga bulan periode pembibitan.

Tabel 6. Jumlah akar lateral dan panjang akar lateral bibit tanaman kelor dari berbagai fase pindah tanam semai

\begin{tabular}{lcccccc}
\hline \multirow{2}{*}{\multicolumn{1}{c}{ Perlakuan }} & \multicolumn{3}{c}{ Jumlah akar lateral saat umur } & \multicolumn{3}{c}{ Panjang akar (cm) lateral saat umur } \\
\cline { 2 - 7 } & $30 \mathrm{hspt}$ & $60 \mathrm{hspt}$ & $90 \mathrm{hspt}$ & $30 \mathrm{hspt}$ & $60 \mathrm{hspt}$ & $90 \mathrm{hspt}$ \\
\hline Biji langsung tanam & 8.40 & 18.60 & 24.40 & 4.98 & 6.15 & 5.05 \\
Semai fase pancing & 8.80 & 18.20 & 17.80 & 5.16 & 6.04 & 5.48 \\
Semai fase jarum & 11.20 & 16.00 & 19.80 & 4.74 & 5.95 & 5.60 \\
Semai fase kuncup & 7.60 & 13.40 & 22.20 & 6.27 & 5.28 & 5.17 \\
Semai fase daun pertama & 6.00 & 15.00 & 12.00 & 6.38 & 4.93 & 6.82 \\
mekar sempurna & & & & & & \\
\hline \multicolumn{1}{c}{ BNJ 5\% } & - & - & - & - & - & -
\end{tabular}

Pada Tabel 6 tampak bahwa pindah tanam semai berpengaruh tidak nyata terhadap jumlah akar lateral bibit kelor selama tiga bulan periode percobaan. Begitu juga pada pengamatan panjang akar lateral bibit kelor, saat pindah tanam semai berpengaruh tidak nyata terhadap panjang akar lateral selama periode percobaan.

Pada Tabel 7 tampak bahwa pindah tanam semai berpengaruh tidak nyata terhadap panjang akar primer bibit kelor selama tiga bulan periode percobaan. Pada Tabel 8 tampak bahwa pada bibit unur $30 \mathrm{hspt}$, semai yang dipindah tanam pada fase mekar daun pertama mekar sempurna memiliki rasio yang paling tinggi (2.93) dan tidak berbeda nyata dengan bibit yang dipindah pada fase kuncup dan pada bibit umur 60 hspt. Biji langsung tanam 
memiliki rasio tertinggi (0.92), sedangkan pada umur bibit 90 hspt saat pindah tanam semai berpengaruh tidak nyata terhadap rasio tajuk/akar.

Tabel 7. Panjang akar primer bibit tanaman kelor dari berbagai fase pindah tanam semai

\begin{tabular}{lccc}
\hline \multirow{2}{*}{ Perlakuan } & \multicolumn{3}{c}{ Panjang akar primer $(\mathrm{cm})$ saat umur (hspt) } \\
\cline { 2 - 4 } & 30 & 60 & 90 \\
\hline Biji langsung tanam & 13.78 & 16.78 & 18.46 \\
Semai fase pancing & 13.76 & 17.24 & 17.72 \\
Semai fase jarum & 10.38 & 11.88 & 18.28 \\
Semai fase kuncup & 12.00 & 12.62 & 15.22 \\
Semai daun pertama & 13.36 & 12.10 & 15.86 \\
mekar sempurna & & & \\
\hline \multicolumn{1}{c}{ BNJ 5\% } & - & - & - \\
\hline
\end{tabular}

Tabel 8. Rasio tajuk/akar bibit tanaman kelor dari berbagai fase pindah tanam semai

\begin{tabular}{lccc}
\hline \multirow{2}{*}{ Perlakuan } & \multicolumn{3}{c}{ Rasio tajuk/akar saat umur (hspt) } \\
\cline { 2 - 4 } & 30 & 60 & 90 \\
\hline Biji langsung tanam & $0.92 \mathrm{~b}$ & $2.26 \mathrm{~b}$ & 1.19 \\
Semai fase pancing & $1.35 \mathrm{~b}$ & $1.30 \mathrm{~b}$ & 0.82 \\
Semai fase jarum & $1.42 \mathrm{~b}$ & $1.29 \mathrm{~b}$ & 1.15 \\
Semai fase kuncup & $1.58 \mathrm{ab}$ & $1.55 \mathrm{~b}$ & 1.44 \\
Semai fase daun pertama & $2.93 \mathrm{a}$ & $2.60 \mathrm{a}$ & 1.57 \\
mekar sempurna & & & - \\
\hline \multicolumn{1}{c}{ BNJ 5\% } & 1.38 & 0.31 & -
\end{tabular}

Keterangan: Angka-angka diikuti notasi yang sama pada kolom umur tanam yang sama berbeda tidak nyata berdasarkan uji BNJ pada taraf 0,05

Tabel 9. Laju pertumbuhan bibit tanaman kelor dari berbagai fase pindah tanam semai

\begin{tabular}{lcc}
\hline \multirow{2}{*}{ Perlakuan } & \multicolumn{2}{c}{ Laju Pertumbuhan $(\mathrm{g} / \mathrm{ming} g u)$} \\
\cline { 2 - 3 } & Akar & Tajuk \\
\hline Biji langsung tanam & 0.8918 & 0.8262 \\
Semai fase pancing & 0.9636 & 0.8644 \\
Semai fase jarum & 0.8064 & 0.8166 \\
Semai fase kuncup & 0.9310 & 0.9258 \\
Semai fase daun pertama mekar sempurna & 0.7668 & 0.6498 \\
\hline BNJ 5\% & - & - \\
\hline
\end{tabular}

Pada Tabel 9 tampak bahwa saat pindah tanam semai berpengaruh tidak nyata terhadap laju pertumbuhan bibit tanaman kelor baik berat kering tajuk maupun akar, semua perlakuan memiliki laju pertumbuhan yang sama-sama baik.

Pada akhir percobaan ini tidak ada pengaruh yang nyata saat pindah tanam semai. Semua perlakuan mempunyai kemampuan adaptasi yang sama ketika setelah dilakukan pindah tanam. Berbagai fase pindah tanam semai tidak berpengaruh terhadap pertumbuhan bibit kelor.

Penanaman biji atau benih secara langsung menyebabkan tanaman tumbuh dengan baik karena tanaman tidak perlu melakukan penyesuaian pada lingkungan. Sedangkan 
penanaman dari berbagai fase pindah tanam semai harus melakukan penyesuaian terhadap lingkungan yang baru. Seiring dengan berjalannya waktu, bibit dari berbagai tahap perkembangan semai mampu beradaptasi dengan baik pada ligkungannya. Datta (1991), menyatakan bahwa pindah tanam yang dilakukan pada umur semai yang lebih muda dapat mengurangi kerusakan bibit, tanaman tidak mengalami stagnasi dan pertumbuhan tanman lebih cepat. Penggunaan bibit muda berdampak positif karena lebih mudah beradaptasi dan tidak gampang stres. Ini dikarenakan perakaran belum panjang (Berthman, 2002). Xu et al. (2010), menyatakan bahwa umur bibit yang lebih tua mencerminkan bahwa kemampuan beradaptasi dengan lingkungan semakin cepat.Semakin cepat tanaman beradaptasi, produktivitas semakin cepat.

Hartmann et al. (2002), menyatakan bahwa pindah tanam semaian yang terlambat akan menyebabkan bibit mengalami penyesuaian yang cukup lama untuk kemudian tumbuh dan berkembang. Hal ini sesuai dengan hasil penelitian Santoso dan Purwoko (2008), pada tanaman jarak pagar bahwa, pindah tanam yang paling baik dilakukan pada umur semai 3-10 hari setelah tanam benih atau saat fase mulai berkecambah hingga semai berbentuk pancing, karena jika pindah tanam dilakukan terlambat atau penyapihan pada saat semai telah berakar akan menyebabkan terputusnya beberapa akar yang telah terbentuk, baik akar tunjang maupun akar lateral dan sulit mengatur posisi akar di dalam polibag.

Pada tanaman sawi, pindah tanam yang paling baik dilakukan pada saat umur bibit lebih tua. Hal itu dikarenakan pada saat pada fase awal pertumbuhan (intial phase) bibit yang lebih tua mampu lebih cepat beradaptasi terhadap stagnasi tanaman. Rambut akar tanaman yang lebih banyak menyerap air dan unsur hara didalam tanah untuk proses pertumbuhannya dan diameter batang yang lebih besar menandakan tanaman tersebut memiliki cadangan makanan sehingga bibit yang lebih tua lebih cepat beradaptasi dengan lingkungan (Firmansyah, 2003).

Sedangkan pada tanaman kelor, semua stadia umur semai mampu beradaptasi dengan lingkungan ketika dilakukan pindah tanam. Hal ini diduga karena tanaman kelor memiliki sistem perakaran yang berbeda dengan tanaman tahunan pada umumnya. Akar lateral tanaman kelor akan tumbuh membengkak menyerupai akar primer. Krisnadi (2015), menyatakan bahwa tanaman kelor memiliki akar tunggang berwarna putih dan membesar seperti lobak. Akar yang berasal dari perbanyakan menggunakan biji mengembang menjadi bonggol, membengkak, berakar tunggang warna putih dan memiliki bau yang khas.Tanaman kelor yang diperbanyak melalui biji (generatif) akan memiliki perakaran yang dalam, membentuk akar tunggang yang lebar dan serabut yang tebal,sehingga sulit membedakan akar primer dan lateral. Bulu akar akan tumbuh dari akarlateral sehingga menyebabkan tanaman kelor mampu beradaptasi jika ditanam langsung atau ketika dilakukan pindah tanam dari umur semai muda atau tua yaitu dari fase pancing sampai fase mekar daun sempurna.

Tanaman kelor juga mampu tumbuh dan berkembang dengan baik pada berbagai jenis lingkungan sehingga tanaman ini dikatakan sebagai tanaman ajaib. Simbolan et al. (2007), menyatakan bahwa tanaman kelor mampu hidup pada berbagai jenis tanah, tidak memerlukan perawatan yang intensip dan tahan terhadap musim kemarau. Mendita-Araical et al. (2013), menambahkan bahwa tanaman kelor dapat tumbuh pada daerah tropis dan subtropis pada semua jenis tanah dan tahan terhadap musim kering dengan tahan terhadap kekeringan sampai enam bulan. 
Pertumbuhan bibit tanaman yang baik dipengaruhi oleh sistem perakaran yang normal dan kuat. Dengan sistem perakaran yang baik akan menyebabkan tanaman mampu menyerap unsur hara dan air dengan baik sehingga bibit akan mampu tumbuh dan beradaptasi dengan lingkungannya. Hal ini menunjukkan bahwa pada setiap tahap perkembangan semai siap untuk dipindah tanam. Penelitian ini tidak sejalan dengan apa yang dikatakan Santoso dan Parwata (2017) bahwa sebaiknya stadia pindah tanam semai sebaiknya dilakukan pada saat fase jarum karena tahan kekeringan dan mudah beradaptasi dengan baik.

Tanaman yang diperbanyak dengan biji mempunyai pertumbuhan yang sangat lamban pada awal karena pertumbuhan lebih kepada pengembangan akar sehingga tanaman sangat rentan terhadap persaingan dengan gulma.Setelah akar tumbuh dengan baik tanaman menjadi lebih kokoh, tumbuh dengan cepat, tahan kekeringan dan mampu mengasilkan biomasa daun yang tinggi (Krisnadi, 2015). Rijssenbeek (2006) melaporkan bahwa penanaman biji secara langsung menyebabkan pertumbuhan yang sangat lambat dan presentase gagal tumbuh yang sangat tinggi. Hanya bilamana kondisi yang sangat optimal, seperti ketersediaan kelembaban tanah yang cukup dan persiapan lubang tanam yang optimal serta penanaman biji lebih dari satu tiap lubang tanam, maka penanaman biji secara langsung akan berhasil.

Sehubung dengan tidak ada pengaruh nyata dari berbagai fase pindah tanam semai, namun jika ditinjau dari aspek agronomi, pindah tanam semai fase pancing dan jarum merupakan fase pindah tanam yang lebih baik karena lebih mudah dilakukan, waktu lebih cepat, resiko patahnya akar lebih sedikit. Bilamana pindah tanam dilakukan terlambat atau pada fase daun pertama mekar sempurna, resiko patahnya akar lebih tinggi, waktu pindah tanam lebih lama, perawatan semai lebih lama sehingga merugikan dari aspek ekonomi. Penanaman biji secara langsung memiliki resiko tidak tumbuhnya bijisehingga harus dilakukan penyulaman yang menyebabkan pertumbuhan bibit tidak seragam dibandingkan dengan melakukan persemaian terlebih dahulu. Ini akan menghemat waktu, tenaga dan biaya. Penanaman biji secara langsung tetap dapat dilakukan selama kualitas dan viabilitas biji yang digunakan berkualitas tinggi.

Terkait dengan nilai rasio tajuk/akar yang merupakan manifestasi dari perbandingan pertumbuhan tajuk terhadap akar, maka bibit yang dipindah tanam pada fase pancing dan jarum merupakan bibit yang memiliki kualitas lebih baik. Semakin kecil nilai (mendekati nilai 1), maka bibit dikatakan memiliki potensi daya adaptasi yang baik setelah pindah tanam di lapang produksi. Santoso dan Purwoko (2008), menyatakan bahwa bibit jarak pagar asal biji yang memiliki nilai rasio yang mendekati satu atau nilai rasio yang lebih kecil merupakan bibit jarak pagar yang memiliki kualitas lebih baik.

\section{KESIMPULAN}

Saat pindah tanam semai berpengaruh tidak nyata terhadap pertumbuhan bibit kelor, namun jika ditinjau pada aspek praktis agronomi, maka sebaiknya pindah tanam dilakukan pada saat fase pancing hingga fase jarum. 


\section{DAFTAR PUSTAKA}

Bertham, Y.H. 2002. Respon Tanaman Kedelai (Glycine Max L. Merill) Terhadap Pemupukan Fosfor dan Kompos Jerami Ultisol. Jurnal Ilmu Pertanian Indonesia 4(2):78-83

Datta, D. 1991. Principles and Practices of Rice Production. John Wiley and Sons Inc. New York.

Firmansyah, F. 2003. Pertumbuhan dan Produktifitas Sawi Pak Choy (Brasica rapa L.) Pada Umur Transplanting dan Pemberian Mulsa Organik. Fakultas Pertanian Universitas Brawijaya.

Hartmann, H.T., D.E. Kester, F.T. Davies, Jr., R.L. Geneve. 2002. Plant Propagation: Principles and Practices. 7th edition. Printice Hall Inc. 770p.

Krisnadi, A. D. 2015. Kelor Super Nutrisi.Kelorina.com. [Diakses pada 17 November 2016].

Pelupessy, L. 2007. Teknik Pembibitan. Panitia Implementasi Program NFP-FAO Regional Maluku \& Maluku Utara, Editor: Fakultas Pertanian Universitas Pattimura.

Rijssenbeek, W. 2006. Jatropha Planting Mannual. Handbook on Jatropha curcas. FACT Foundation. www.fact-fuaels.org [September 2017].

Santoso, B.B.,Purwoko, B.S. 2008. Tehnik Pembibitan Tanaman Jarak Pagar (Jatrophacurcas L). CropAgro, 1(2):25-33

Santoso, B.B., Parwata, IGMA. 2017. Viabilitas Biji dan Pertumbuhan Bibit Kelor (Moringaoleifera Lam.). J. Sains Teknologi \& Lingkungan, 3(2):1-8 DOI: https://doi.org/10.29303/jstl.v3i2.18

Santoso, B.B., Parwata, IGMA., Soemeinaboedhy, IN. 2017. Pembibitan Tanaman Kelor (Moringa oleifera Lam). Arga Puji Press. 79p.

Tiea, J., Jianga M., Lia H., Zhanga S., Zhangb X. 2015. A Comparasion Between Moringa Oleifera Seed Presscake Extract Andpolyaluminium Chloride in The Removal of Direct Black 19 Fromsyntetic Wastewater. J. Industrial Crops and Products. 74: 530534

Xu, Q.C., H.L. Xu, F.F. Qin, J.Y. Tan., G. Liu and S. Fujiyama. 2010. Relay-Intercropping into Tomato Decreases Cabbage Pest Incidence. Journal of Food, Agriculture and Enviroment. 8(4):1037-1041. 